\title{
CH. WOLFF E I. KANT SOBRE VERDADE TRANSCENDENTAL
}

\author{
Joäosinho Beckenkamp*
}

SÍNTESE - Nos últimos anos, alguns autores alemães (como N. Hinske e outros) vêm investigando a origem do termo transcendental tal como usado por Kant. O presente artigo procura mostrar a ascendência wolffiana, e mesmo escolástica, do uso kantiano deste termo.

\begin{abstract}
Recently some german authors (N. Hinske) started investigations concerning the origin of the kantian use of the term transcendental. This article shows that Kant's use of the term relates to the wolffian metaphysics and, beyond, to the medieval scolastics.
\end{abstract}

I - A distinção entre o imanente e o transcendente, desde que devidamente estabelecida pela filosofia escolástica, não apresenta maiores dificuldades à compreensão. Já não acontece o mesmo com uma outra distinção, também nascida das sutilezas dos escolásticos, a distinção entre o transcendente e o transcendental.

Nos limites da filosofia escolástica ainda não se dá a dificuldade de delimitar o que se entenda precisamente por transcendental. Só no momento em que este conceito conhece sua entrada triunfal para o âmbito da filosofia moderna, com o programa de uma filosofia transcendental de Immanuel Kant, torna-se um problema o sentido e a extensão em que deve ser tomado, a ponto de motivar, nos últimos anos, todo um campo de pesquisa envolvido na árdua tarefa de elucidar o que deva ser entendido pelo termo transcendental e qual a natureza de uma filosofia transcendental, ainda concebida como um programa de futuro.

Este artigo procura trazer para os estudiosos da filosofia transcendental em Língua Portuguesa alguns momentos que terão tido grande importância na formulação kantiana de um programa transcendental na Filosofia. Que Kant tenha começado sua reflexão filosófica de dentro da escola wolffiana, não precisa ser lembrado aqui. O que se verá é a apreciação de uma possivel evolução da filosofia de Wolff para a de Kant num ponto bem específico, o pertinente à noção de transcendental.

Para tanto comentar-se-á, num primeiro momento (II), a noção wolffiana de verdade transcendental e seu contexto sistemático. Em seguida (III), traço algumas considerações sobre o transcendental em Kant, sempre dentro dos limites de uma possível evolução a partir do sistema wolffiano. Por fim (IV) são anexados, em tra-

Professor da Universidade do Vale do Rio dos Sinos - UNISINOS - São Leopoldo, RS.

\begin{tabular}{|l|l|l|l|l|l|}
\hline VERITAS & Porto Alegre & v. 41 & $\mathrm{n}^{2} 161$ & Março 1996 & p. 57-64 \\
\hline
\end{tabular}



Wolff, para facilitar seu uso também ao leitor português.

II - Para marcar a importância da noção de verdade transcendental na filosofia de Wolff basta apontar para o caráter derivado que tem, em seu sistema, a verdade lógica, verdade de proposições, com relação à verdade transcendental. ${ }^{1}$ Sem verdade transcendental não haveria verdade lógica, ou seja, não nos seria possível enunciar juizos sobre as coisas com pretensão à verdade.

A verdade transcendental é definida por Wolff com referência à noção de ordem. ${ }^{2}$ No texto latino, sempre mais próximo da terminologia e da doutrina escolásticas, ela é dada como a ordem de tudo o que pode convir a um ente em si mesmo. ${ }^{3}$ Neste contexto escolástico Wolff pode falar da verdade dos entes, que nada mais é que a ordem interna dos predicados essenciais, dos atributos e dos modos, duplamente regida pelos princípios de não-contradição e de razão suficiente. ${ }^{4} \mathrm{~A}$ contradição entre diversos predicados do ente mostrá-lo-ia como um não-ente, posto que o ente é definido como aquilo que é possível, ${ }^{5}$ e o que implica contradição é impossivel. ${ }^{6}$ Os predicados essenciais do ente encontram em sua definição a razão suficiente de sua pertinência ao ente. Por outro lado os predicados não essenciais do ente, os diversos atributos e modos, devem também ser regidos pelo princípio de razão suficiente, pois caso contrário poderiam apresentar-se em desordem uns com relação aos outros. A noção de verdade transcendental, tal como definida por Wolff, baseia-se, pois, sobre a validade universal dos princípios de nãocontrađição e de razão suficiente.

A partir disto compreende-se o sentido do dito no $\$ 499$ da Ontologia com relação à possibilidade da verdade lógica fundar-se na verdade transcendental. A verdade lógica de proposições universais consiste, para Wolff, na determinabilidade do predicado pela noção do sujeito. ${ }^{7}$ Se pudesse haver contradição entre os diversos caracteres componentes da noção do sujeito e sua correlação não tivesse uma razão suficiente, não seria dada também uma razão suficiente porque o predicado pertence ao sujeito em vez de não lhe pertencer, ou seja, o predicado não seria de-

1. Na Ontologia Wolff enfatiza este aspecto, que em sua metafisica alemã é mais pressuposto: "Si nulla datur in rebus veritas transcendentalis, nec datur veritas logica propositionum universalium, nec singularium datur nisi in instanti". (Philosophia Prima sive Ontologia). Frankfurt/Leipzig, 1736. Reimpressão: Hildesheim, G. Olms, 1962, § 499).

2 O sistema wolffiano pode ser considerado o último dos grandes sistemas escolásticos, nos quais a noção de ordem sempre ocupa um lugar central. Mas a continuidade de determinados elementos do sistema não implica a inexistência de fundamentais variações de outros elementos. Neste sentido seria interessante estudar as analogias e diferenças sistemáticas da noção de ordem na filosofia medieval, na escolástica barroca e, finalmente, na filosofia wolffiana. Sem dúvida a noção de ordem de Wolff, e por conseguinte também de Leibniz, é tributária daquelas outras sob muitos aspectos.

3 "Veritas adeo, quae transcendentalis appellatur \& rebus ipsis inesse intelligitur, est ordo in varietate eorum, quae simul sunt ac se invicem consequuntur, aut, si mavis, ordo eorum, quae enti conveniunt" (Ontologia § 495).

Cf. Ontologia $\S 497$. Neste sentido a filosofia escolástica fala da verdade como um transcendental, expresso na formulação geral: omne ens est verum.

5 Cf. Ontologia $\$ 134$.

6 Cf. Ontologia $\$ \$ 79$ e 85.

7 Cf. Philosophia rationalis sive logica, § 513. Frankfurt, 1728 (Não existe ainda reimpressão da lógica latina de Wolff). 
terminado pela noção do sujeito e, por conseguinte, não se poderia falar da verdade de proposições universais. Já a verdade lógica de proposições singulares ficaria restrita ao instantâneo, se sem razão suficiente o individuo pudesse mudar de um momento para o outro suas características. Neste sentido a verdade lógica das proposições, tanto universais quanto singulares, pressupõe a verdade transcendental dos entes.

Agora, a determinação do pređicado pela noção do sujeito pode dar-se de duas formas distintas: ou o predicado é parte daquele conjunto de características que constituem o sujeito enquanto espécie, sendo, portanto, parte de sua definição, ou o predicado é pertinente ao sujeito enquanto este é considerado em sua relação com o resto do universo. ${ }^{8}$ No primeiro caso o predicado pertence ao sujeito considerado em si (in se), no segundo, o predicado é determinado pelo sujeito enquanto considerado em suas relações com outros sujeitos (in nexu). Como estas relações são pensadas em termos de uma harmonia preestabelecida de todos os momentos do universo (nisto Wolff segue meio cauteloso a Leibniz), deve-se procurar no sujeito também o momento da determinação das características não essenciais ou definitórias, ou seja, mesmo não sendo constitutivas do sujeito como espécie estas características lhe pertencem, porque o constituem em sua relação com 0 resto do universo. Para Wolff, como para Leibniz, não existem relações físicas, mas apenas metafísicas, relações preestabelecidas na harmonia do melhor dos mundos possiveis.

Com isto Wolff já está transformando a noção escolástica de verdade transcendental, dando-lhe uma interpretação racionalista (inspirada fortemente em Leibniz). Mais fundamental, contudo, é a transformação por que passa esta noção ao ser relida no contexto da diferenciação cartesiana entre verdade e sonho. Interpretando 0 Descartes das Meditações, Wolff coloca a ordem e a desordem como critério de distinção entre a verdade e o sonho: se no sonho os diversos momentos podem se apresentar de forma caótica, confusa e desordenada, não assim na verdade, onde tudo deve estar relacionado com tudo em perfeita ordem. ${ }^{9}$

Desta reinterpretação da noção escolástica de verdade transcendental como ordem de tudo aquilo que pertence a uma coisa, ordem esta que permite afirmar que não estamos num dado momento sonhando, parte a definição de verdade do texto da metafísica wolffiana em língua alemã. ${ }^{10} \mathrm{~A}$ verdade distingue-se do sonho pela ordem, podendo ser definida como a ordem na sucessão dos diversos momentos pertinentes à coisa. ${ }^{11} \mathrm{O}$ critério que nós temos para julgar se algo está em or-

\section{Cf. Ontologia § 499 .}

Cf. Ontologia $\$ \S 493$ e 494.

Costuma-se chamar de Deutsche Metaphysik (Metafísica Alemã) a exposição por Wolff do todo da metafisica (geral e especial) em alemão, para abreviar seu longo título: Vernünftige Gedancken von Gott, der Welt und der Seele des Menschen, auch allen Dingen überhaupt. Halle. 1720. (Reimpressão da edição de 1751: Hildesheim, G. Olms, 1983).

Cf. Deutsche Metaphysik § 142. É bem verdade que Wolff não usa aqui a expressão verdade transcendental, mas em termos de conteúdo trata-se deste mesmo tema escolástico (havendo, além disto, perfeita correspondência das duas definições na ordem de exposição da Ontologia e da parte da Metafísica Alemã que trata da Ontologia). Aliás, em geral os textos que Wolff escreveu em alemão procuram evitar a terminologia escolástica, tendendo a se aproximar mais da cartesiana e leibniziana. 
dem com o resto é, por seu turno, o princípio de razão suficiente: enquanto não encontramos a razão da presença ou ausência ou ainda da modificação de uma característica da coisa não apreendemos a ordem em que ela se encontra na coisa. Se a verdade da coisa nada mais é, pois, do que a ordem dos diversos momentos constituintes da coisa, é conseqüente afirmar que sem o princípio de razão suficiente não existe verdade, como Wolff faz no $\S 144$ da Metafísica Alemã. Além do mais conhecer a verdade da coisa será compreender a razão pela qual algo é assim ou assado, quer dizer, encontrar as regras da ordem que se encontra nas coisas e suas modificações. ${ }^{12} \mathrm{O}$ conhecimento da ordem, e por conseguinte da verdade, dá-se no reconhecimento das regras que constituem a ordem da coisa.

A ordem, enfim, nada é senão a semelhança encontradiça no modo como estão colocadas as coisas umas ao lado das outras ou umas após as outras. ${ }^{13}$ Reparese que se trata não de uma ordem de natureza epistemológica, estabelecida pelo intelecto sobre uma multiplicidade de elementos aparentemente divergentes, mas de uma ordem de natureza ontológica, ordem das coisas em si mesmas e em suas relações com o resto do universo, a ser reconhecida pelo intelecto no ato de intelecção.

III - Numa das primeiras ocorrências do termo transcendental num texto kantiano vemo-lo sendo empregado como sinônimo do termo metafísico. ${ }^{14}$ Em vários momentos dos textos latinos, Wolff também emprega metafísico e transcendental como termos intercambiáveis, seguindo nisto um uso aparentemente estabelecido por vários sistemas escolásticos dos séculos XVI e XVII. ${ }^{15}$

Curiosamente Kant é levado a distinguir entre o metafísico e o transcendental em suas reflexões sobre Metafísica ao longo dos anos 1760 e $70,{ }^{16}$ porque uma tal distinção é feita pela Metaphysica de Baumgarten, que lhe serve de manual de referência em suas aulas. Nos parágrafos 73, 89, 98 e 100 de sua Metaphysica Baumgarten apresenta sumariamente os transcendentais do uno, da verdade, da perfeição e do bom, ${ }^{17}$ distinguindo, contudo, no $\S 89$ entre a verdade metafísica, com-

12 Cf. Deutsche Metaphysik § 145.

13

Cf. Ontologia § 472 .

14 Trata-se de um pequeno texto sobre os elementos últimos dos corpos físicos, datado de 1756, em que Kant correlaciona metodologicamente a Metafisica e a Geometria no estabelecimento de uma substância simples (um problema fundamental, aliás, da cosmologia racionalista, que pretende poder reconstruir o mundo a partir do conhecimento das substâncias simples). Numa altura do texto Kant emprega metafísica e filosofia transcendental como termos intercambiáveis: "Sed quo tandem pacto hoc in negotio metaphysicam geometriae conciliare licet, cum gryphes facilius equis quam philosophia transcendentalis geometriae iungi posse videantur?" (Monadologia physica; praenotanda).

15 Por exemplo na Ontologia § 502: "Notio veritatis transcendentalis seu metaphysicae distincta, quam dedimus, non contraniatur notioni confusae ejusdem, quae Scholasticis fuit." Em todo o § 502, onde se reporta a Francisco Suarez e a Rudolph Goclenius, Wolff usa ora transcendental ora metafísico, sem a preocupação de separar um do outro.

16 Cf. a este respeito sobretudo as reflexões 3765, 4025-27, 4402 e 4767, todas reproduzidas no vol. XVII da edição das obras de Kant pela Academia Prussiana das Ciências (Berlim/Leipzig. Walter de Gruyter, 1926), onde também encontramos uma reprodução (com exceção da parte pertinente à psicologia empírica, reproduzida no vol. XV das obras de Kant) da Metaphysica de Baumgarten.

17 Com relação a estes dois últimos, Baumgarten parte obviamente do texto de Wolff, que em sua Ontologia (\$ 503) esclarece que o que ele chama de perfeição os escolásticos denominam de bondade transcendental (bonitas transcendentalis). 
preendida como a ordem de vários em um (tal como Wolff definira sua noção de verdade transcendental), e a verdade transcendental, pertinente só aos predicados essenciais e aos atributos do ente, e que é elucidada como a verdade metafísica necessária. Kant fará suas variações sobre esta distinção entre o transcendental e o metafísico e sua relação com a essência das coisas, sem contudo chegar a fixar estas distinções em algum dos textos destinados à publicação.

Na segunda edição da Crítica da Razão Pura Kant retoma esta temática dos predicados transcendentais de todo ente para excluí-los definitivamente da lista de suas categorias. Não sendo nem categorias do entendimento nem idéias da razão pura, as noções transcendentais do uno, verdadeiro e bom adquirem um caráter ambíguo na filosofia crítica de Kant, sendo mesmo difícil considerar o lugar sistemático que deveriam ocupar na filosofia transcendental. A Crítica da Razão Pura apresenta duas possibilidades neste sentido.

A primeira é dada pelo próprio § 12, onde Kant exclui sua pertinência à tábua das categorias. Kant lhes nega de saída o caráter ontológico que tinham na metafísica tradicional: "Estes supostos predicados transcendentais das coisas nada mais são que exigências e critérios lógicos de todo conhecimento das coisas em geral". ${ }^{18}$ As noções de unidade, verdade e bondade transcendentais passam, pois, por uma nova transformação com a "revolução copernicana" empreendida por Kant na Metafísica: não dos entes como tais deve-se predicar a necessária unidade, verdade e bondade, mas do nosso conhecimento dos entes. A unidade, a verdade e a bondade são transcendentais do sujeito e não do objeto do conhecimento. No citado § 12 Kant procura reduzir estas noções às categorias da quantidade (unidade, pluralidade e totalidade), das quais seriam extrapolações formais, sendo estendidas a todo conhecimento possível. Trata-se, pois, mais de uma determinação negativa (que elas não são categorias).

Por outro lado, Kant continua operando com elas em suas análises transcendentais, como quando fala em unidade transcendental da apercepção ou da autoconsciência, ou em unidade transcendental da síntese do múltiplo na imaginação. Creio ser possivel ler esta nova linguagem introduzida por Kant como uma transformação (agora subjetivo-transcendental) da maneira de falar da tradição escolástica, sendo agora transferido para o nivel da consciência e do sujeito o que antes se costumava procurar no e atribuir ao objeto. E assim dever-se-ia ver com certo ceticismo a pretensa exportação das noções transcendentais do âmbito da filosofia transcendental kantiana; exatamente por estarem fora da tábua das categorias, Kant pode operar com elas como uma espécie de metacategorias.

Restrinjo-me a concluir com o emprego que Kant continua fazendo da noção de verdade transcendental. Evidentemente não se tratará de uma verdade transcendental de todo ente, como na tradição escolástica, mas de algo pertinente ao sujeito do conhecimento empírico. Assim escreve Kant na Crítica da Razão Pura: "No conjunto de toda experiência possivel encontram-se, porém, todos os nossos conhecimentos, e na referência geral à mesma consiste a verdade transcendental, que precede toda verdade empírica e a torna possível". ${ }^{19}$ Vimos que para Wolff

18 Kritik der reinen Vernunft B 113-4.

19 KrV B 185/A146. 
também a verdade transcendental fundava a verdade lógica ou das proposições, só que no seu caso isto significava que a ordem imanente do ente torna possivel uma proposição ser verdadeira ou falsa, ou seja, a ordem da coisa é que possibilita a ordem do conhecimento e, por conseguinte, o próprio conhecimento (a verdade transcendental sendo tomada num sentido ontológico). Para Kant a verdade transcendental não diz respeito à ordem dos entes, mas à ordem interna do sujeito do conhecimento empírico e neste sentido à ordem deste próprio conhecimento, a qual somente torna possivel um objeto do conhecimento, também chamado de objeto transcendental (a verdade transcendental sendo tomada num sentido epistemológico). A verdade transcendental passa a se situar no âmbito da experiência possível, sendo tudo o que supõe uma experiência real da esfera das verdades empíricas. Neste sentido pode Kant falar da verdade transcendental dos conceitos puros do entendimento, na medida em que estes são condições de possibilidade de toda experiência, isto é, fazem-se necessários em toda experiência "possível". Assim a propósito das categorias da substância e da causalidade escreve Kant: "É, pois, somente por estes conceitos expressarem a priori as relações das percepções em toda experiência que se conhece sua realidade objetiva, i.é, sua verdade transcendental, e, embora sem dúvida independente da experiência, ainda assim não independente de toda referência à forma de uma experiência em geral" ${ }^{20} \mathrm{Na}$ medida em que se reconhece que as categorias são componentes da forma intelectual de toda experiência possivel, conhece-se sua verdade transcendental. Esta consiste, pois, na referência à experiência possível, mais exatamente à sua forma como experiência em geral. $\mathrm{O}$ um a que muitos têm de ser relacionados para constituírem a verdade transcendental não é mais a ordem dos entes (como para Wolff), mas a coerência interna da forma da experiêncla, que sempre pressupõe já a atividade do sujeito que conhece.

Considerando-se o uso que Kant continua fazendo das noções de unidade e verdade transcendentais, não é exagerado afirmar que o transcendental kantiano resulta de uma transformação e subseqüente extrapolação da noção escolástica đo transcendental. A unidade, verdade e bondade transcendentais de todas as coisas, que antes radicavam na sabedoria do intelecto e na bondade da vontade divinas, são transferidas para o âmbito do sujeito da experiência ou do conhecimento empírico, passando a significar a referência à forma geral da experiência possível. A partir desta transformação elementar Kant constrói então toda uma filosofia transcendental, destinada a expor os diversos momentos que compõem esta forma de toda experiência possivel da parte do sujeito do conhecimento.

IV - A obra de Kant é de acesso muito mais fácil do que a de Wolff (estando suas obras mais importantes já traduzidas para o Português) e isto não sem razão. Comparado com os grandes filósofos da tradição ocidental, Wolff é uma figura menor, sendo sua importância praticamente uma histórica, como sistematizador de uma linguagem e preparador de um certo tipo de desenvolvimento que levaria ao idealismo alemão no fim do séc. XVIII. Não havendo tradução de textos de Wolff para o Português, é útil apresentar no caso em tradução portuguesa os parágrafos que dizem respeito à noção de verdade transcendental na Metafísica Alemã de 
Wolff. Segue uma tradução integral de alguns parágrafos deste texto que dizem respeito às noções de ordem e de verdade:

"§ 132. Quando muitos são considerados em conjunto como um e se encontra no modo como seguem um ao lado do outro e um após o outro algo semelhante, então surge disto uma "ordem" de modo que a "ordem" nada mais é que a semelhança do múltiplo em sua seqüência um ao e após o outro.

§ 133. Para que se compreenda isto corretamente, posto ser muito importante, como se verá logo com detalhes, quero ilustrá-lo com um exemplo. Diz-se que as pessoas vão ordenadamente em uma procissão, quando vão par a par, o mais distinto à direita, o menos distinto à esquerda, e igualmente os mais distintos nos pares da frente e os não tão distintos nos seguintes. No que consiste, pois, aqui a ordem? Sem dúvida naquilo pelo qual a ordem seria suspensa se fosse retirado. Ago$\mathrm{ra}$, a ordem seria suspensa, se não os deixo mais andar em pares nem de acordo com a posição uns ao lado e uns após os outros, isto é, falando geralmente da coi$\mathrm{sa}$, quando retiro aquilo em que as diversas coisas, que se deixam distinguir aqui e que seguem umas após e também umas ao lado das outras, se assemelham umas às outras. De acordo com isto fica claro que a ordem em geral não pode ser outra coisa senão a semelhança do múltiplo na seqüência um ao lado e um após o outro. Justo isto se mostra, quando se observa em que consiste a ordem pela qual os hóspedes sentam uns ao lado dos outros à mesa, ou a ordem que se observa em seus afazeres e assim por diante.

$\S 136$. Se quero, pois, saber se algo é desordenado ou não, devo 1. distinguir com exatidão tudo o que, tratado em conjunto como um, deixa-se distinguir e que se considera como parte do todo. Depois devo 2. comparar aquilo que se pode observar em cada uma destas partes na medida em que tem sua própria posição; desta forma encontrar-se-á o que elas têm de idêntico. Encontra-se então em todas estas partes deste conjunto algo idêntico, então se encontra nisto uma semelhança e desta forma descobriu-se a ordem e se pode explicá-la a outros, inclusive afirmála contra os que a põem em dúvida e defendê-la contra todas as objeções.

$\S 140$. Se então se quer conhecer uma ordem, deve-se investigar a razão pela qual muitas coisas seguem desta maneira umas ao lado e umas após as outras e observar nisto, se é sempre a mesma ou se varia sempre da mesma maneira. Os exemplos dados anteriormente podem servir de ilustração.

§ 141. Desta maneira encontra-se em toda ordem regras gerais, pelas quais ela é julgada. E onde então se procede ordenadamente, segue-se regras.

$\S 142$. Porque tudo tem sua razão suficiente, pela qual é, deve também existir sempre uma razão suficiente por que em coisas simples as modificações seguem umas às outras desta e não de outra maneira, em coisas compostas as partes se encontram umas ao lado das outras desta e não de outra forma, também suas modificações seguem umas às outras desta e não de outra maneira. Assim sendo, encontra-se aqui a mesma ordem que pode ser encontrada na exposição ordenada de uma demonstração. Como, no entanto, uma tal ordem não é encontrada no sonho, onde não se consegue por simples experiência indicar a razão por que as coisas estão juntas e umas ao lado das outras de uma determinada maneira, nem por que suas modificações seguem umas às outras, conhece-se disto distintamente que a verdade se distingue do sonho pela ordem. E assim a "verdade" nada é senão a or- 
dem nas modificações das coisas: o sonho, ao contrário, é desordem nas modificações das coisas.

§ 143. Para que isto seja entendido ainda melhor, acho necessário ilustrar a diferença entre a verdade e o sonho com um exemplo claro e distinto. Suponha-se que um grupo se reúna em boa diversão e volte a se separar após algum tempo. Se isto é verdade: então saber-se-á dizer por que cada pessoa está presente e como veio até ali; por que no divertimento tido acontece isto ou aquilo; por que no fim volta-se a se separar. Numa palavia, não acontecerá nada de diferente no grupo sem que se possa dizer por que aconteceu. Ao contrário, se é um sonho, então não saberei dizer por que cada pessoa se encontra presente e como ela pôde vir até ali; pois, se sou o anfitrião, verei visitas não convidadas e mesmo seguidamente estranhas, sim, entre eles enxergarei alguns que conheci em outros tempos em lugares muito distantes ou mesmo que já morreram há muito e já apodreceram debaixo da terra. Ninguém saberá dizer por que se encontram presentes. Uma pessoa poderá transformar-se num instante em outra, sem que possa dizer como isto se deu. Pessoas estarão ausentes sem que tenham se retirado: outras pelo contrário estando ali sem que tenham vindo. O grupo todo estará num outro lugar sem que tenha se levantado e partido. Numa palavra, as modificações que se dão aqui não se fundam umas nas outras, e por isto nunca posso dizer como e por que isto se deu. Se então compararmos a verdade com o sonho e nisto atentarmos para o que os distingue, não se poderá determinar outra diferença a não ser a que dei antes, a saber, que na verdade tudo está fundado em tudo, no sonho não, e por isto, no primeiro caso, as modificações das coisas têm uma ordem, no sonho, ao contrário, só se encontra desordem.

§ 144. Quem considerar isto muito bem reconhecerá sem dúvida que sem o princípio de razão suficiente não pode existir verdade. E por isto se colocará muito menos em dúvida este princípio ou se o terá por suspeito, porque sem ele não se pode mais distinguir entre verdade e sonho.

$\S 145$. Sim, fica claro ainda que se conhece a verdade, quando se entende a razão por que isto ou aquilo pode ser, isto é, as regras da ordem que se encontra nas coisas e suas modificações.

$\S 146$. Porque, então, por tudo, seja nas coisas simples seja nas compostas, estar fundado em tudo se origina uma ordem, encontra-se também em tudo verdade. $\mathrm{E}$ é, por conseguinte, cada coisa algo verdadeiro. Já se o disse há muito, mas nunca se conseguiu mostrá-lo claramente e demonstrá-lo.

$\S 147$. Por isto também se pode apreender das coisas regras gerais, pelas quais se pode esclarecer suas modificações". 